\title{
Discrepancy between Serum Ferritin and Liver Iron Concentration in a Patient with Hereditary Hemochromatosis - The Value of T2* MRI
}

\author{
Mustafa A. Al-Tikrity ${ }^{a}$ Mohamed A. Yassin ${ }^{b}$ \\ aDepartment of Internal Medicine, Hamad Medical Corporation, Doha, Qatar; \\ ${ }^{b}$ Department of Medical Oncology, National Center for Cancer Care and Research, \\ Hamad Medical Corporation, Doha, Qatar
}

\section{Keywords}

Hemochromatosis · Ferritin · Liver iron concentration · MRI

\begin{abstract}
Primary hemochromatosis is an inherited disorder, and the homeostatic iron regulator (HFE) gene $\mathrm{C} 282 \mathrm{Y}$ mutation is a common cause of hemochromatosis in Europe. We are reporting a case of a 56-year-old female known to have hemochromatosis with the HFE gene C282Y mutation with a serum ferritin level of $482 \mu \mathrm{g} / \mathrm{L}$ who underwent heart and liver T2* MRI which showed no evidence of iron overload - neither in the heart nor in the liver. This indicates that there is a discrepancy between serum ferritin and liver iron concentration by MRI and the superiority of T2* MRI in diagnosis and follow-up of iron overload in patients with hereditary hemochromatosis.

\section{Introduction}

Hereditary hemochromatosis $(\mathrm{HH})$ is an autosomal recessive disorder considered as one of the most common inherited (genetic) disorders in the world. It is most commonly due to mutations in the HH gene (HFE). HH occurs when there is an increased intestinal iron absorption causing an increased total-body iron overload. HH has a low penetrance. Two common HFE mutations are observed C282Y (guanine to adenine change at nucleotide 845 in the HFE gene that causes a substitution of cysteine for tyrosine at amino acid 282) and 
H63D (cytosine to guanine change at nucleotide 187 in the HFE gene that causes a substitution of histidine to aspartic acid at amino acid 63) [1-4]. Iron overload can contribute to hemochromatosis but not all individuals with HFE mutations develop iron overload and clinical HH. There are other genetic and/or environmental factors, as well as other medical conditions, dietary iron intake, and blood loss (e.g., from physiologic bleeding such as menstruation or pathologic bleeding) which likely play a role in the manifestation of a clinically significant body iron burden. For those who are affected, classic HH generally does not become clinically manifest until later in adulthood when a significant total-body iron accumulation has occurred [5].

\section{Case Presentation}

A 56-year-old woman, with a known HH C282Y mutation and on phlebotomy when required, moved to Qatar 2 years ago. She was referred to the hematology clinic for further evaluation and to continue the medical care, as well as for an evaluation whether she still required further phlebotomy.

On her initial visit, she seemed to be in a fair general condition, and her clinical examination was not remarkable. Her complete blood count showed a white blood cell count of 6.8 $\times 10^{3} / \mu \mathrm{l}$ (normal range $4-10$ ), $\mathrm{Hb}$ of $14.5 \mathrm{~g} / \mathrm{dL}$ (normal range 12-15), platelets of $208 \times 10^{3} /$ $\mu \mathrm{l}$ (normal range 150-400), serum ferritin of $287 \mu \mathrm{g} / \mathrm{L}$ (normal range 18-340). An MRI of the liver was done which showed no evidence of iron overload: $0.9 \mathrm{mg} / \mathrm{g}$ dry tissue (normal range $0.17-1.8$ ), $16 \mathrm{mmol} / \mathrm{kg}$ dry tissue (normal range $3-33$ ). She was again evaluated 2 years later, when her serum ferritin level was found to be at $482 \mu \mathrm{g} / \mathrm{L}$ (normal range 18-340). Therefore it was decided to do a heart and liver MRI which showed $<1.2 \mathrm{mg}$ iron/g dry weight (no siderosis) in the heart and $3.4 \mathrm{mg}$ iron/g dry weight (no siderosis) in the liver. There was no iron overload neither in the heart nor in the liver, which demonstrates the superiority of $\mathrm{T} 2$ * MRI over serum ferritin.

\section{Discussion}

Chronic blood transfusion is the mainstay of care for individuals with $\beta$-thalassemia major. However, it causes an iron overload that requires monitoring and management by long-term iron chelation therapy to prevent endocrinopathies, liver dysfunction, and cardiomyopathies [6-11], which can be fatal. The hepatic R2 MRI method (FerriScan ${ }^{\circledR}$ ) or T2* MRI has been validated as the gold standard for evaluating and monitoring liver iron concentration (LIC) that reflects the total body iron overload. Although adequate oral iron chelation therapy shows promising results for the treatment of transfusional as well as nontransfusional iron overload, compliance with medication remains an issue $[12,13]$. Iron overload is an inevitable consequence of long-term transfusion therapy, for which iron chelation therapy is indicated and recommended. All patients who receive red blood cell transfusions and iron chelation therapy should be regularly monitored and given practical and educational support in order to improve compliance with therapy $[14,15]$. In both nontransfusional and transfusion-dependent sickle cell disease, monitoring the liver iron status by measuring serum ferritin and LIC, using the FerriScan method, can diagnose early a hepatic iron overload. This helps to decide about starting and tailoring iron chelation accordingly to reduce the risk of developing hepatopathy in these patients [16].

$\beta$-thalassemia intermedia spans a wide spectrum of severity and carries a higher morbidity than previously recognized, including extramedullary hematopoiesis, leg ulcers, 
gallstones, thrombosis, secondary heart failure, pulmonary hypertension, skeletal deformity, growth retardation, and endocrine abnormalities, such as diabetes mellitus, hypothyroidism, osteoporosis, and hypogonadism. A significant number of thalassemia intermedia patients have a high LIC, short stature, and endocrine disorders. Patients who require occasional transfusions have a higher liver iron overload and higher hepatic dysfunction. Females appear to attain a better final adult height and have higher IGF1-SDS versus males [17].

$\mathrm{HH}$ is an autosomal recessive disorder characterized by an excessive intestinal absorption of dietary iron, causing an iron overload in different organs, especially the liver. Hemochromatosis may remain unrecognized until later in life. Patients are usually asymptomatic, but they may present with a variety of signs and symptoms. These include hyperpigmented skin, hepatomegaly, arthralgia, diabetes mellitus, and/or heart failure/arrhythmia. For the risk of HH-related morbidity in HFE mutation carriers [18], serum ferritin levels are not an accurate measure of total body iron stores in HH. The use of T2* MRI should be encouraged in patients with $\mathrm{HH}$ for a better evaluation of iron overload and the avoidance of complications, since the serum ferritin level can be misleading in these conditions [18].

\section{Conclusion}

$\mathrm{HH}$ is known to cause an iron overload which is generally followed up by serum ferritin measurements to decide about phlebotomy; however, in the era of T2* MRI and its reported superiority, T2* MRI should be utilized for the diagnosis and follow-up of patients with an iron overload whenever it is available.

\section{Acknowledgement}

The authors would like to acknowledge the internal medicine residency program for scientific support.

\section{Statement of Ethics}

This case was approved by the Hamad Medical Corporation's Medical Research Center. The patient consented to the publication of his case.

\section{Disclosure Statement}

The authors have no conflicts of interest.

\section{Funding Sources}

This work was funded by Qatar National Library.

\section{Author Contributions}

Both authors contributed equally to writing and editing. 
Al-Tikrity/Yassin: Hemochromatosis and LIC

\section{References}

1 Feder JN, Gnirke A, Thomas W, Tsuchihashi Z, Ruddy DA, Basava A, et al. A novel MHC class I-like gene is mutated in patients with hereditary haemochromatosis. Nat Genet. 1996;13(4):399-408.

2 Pietrangelo A. Genetics, genetic testing, and management of hemochromatosis: 15 years since hepcidin. Gastroenterology. 2015;149(5):1240-e4.

3 Nandar W, Connor JR. HFE gene variants affect iron in the brain. J Nutr. 2011;141(4):729S-39S.

4 McLaren GD, Gordeuk VR. Hereditary hemochromatosis: insights from the Hemochromatosis and Iron Overload Screening (HEIRS) Study. Hematology Am Soc Hematol Educ Program. 2009;195-206.

5 Cairo G, Recalcati S, Montosi G, Castrusini E, Conte D, Pietrangelo A Inappropriately high iron regulatory protein activity in monocytes of patients with genetic hemochromatosis. Blood. 1997;89(7):2546-53

6 Soliman AT, Yasin M, Kassem A. Leptin in pediatrics: a hormone from adipocyte that wheels several functions in children. Indian J Endocrinol Metab. 2012 Dec;16(Suppl 3):S577-87.

7 Soliman A, Yassin M, Al Yafei F, Al-Naimi L, Almarri N, Sabt A, et al. Longitudinal study on liver functions in patients with thalassemia major before and after deferasirox (DFX) therapy. Mediterr J Hematol Infect Dis. 2014;6(1):e2014025.

8 De Sanctis V, Soliman AT, Candini G, Yassin M, Raiola G, Galati MC, et al. Insulin-like growth factor-1 (IGF-1): demographic, clinical and laboratory data in 120 consecutive adult patients with thalassaemia major. Mediterr J Hematol Infect Dis. 2014;6(1):e2014074.

9 De Sanctis V, Soliman A, Candini G, Campisi S, Anastasi S, Iassin M. High prevalence of central hypothyroidism in adult patients with $\beta$-thalassemia major. Georgian Med News. 2013 Sep;(222):88-94.

10 De Sanctis V, Elsedfy H, Soliman AT, Elhakim IZ, Pepe A, Kattamis C, et al. Acquired hypogonadotropic hypogonadism $(\mathrm{AHH})$ in thalassaemia major patients: an underdiagnosed condition? Mediterr J Hematol Infect Dis. 2016;8(1):e2016001.

11 Soliman AT, Yassin M, Majuid NM, Sabt A, Abdulrahman MO, De Sanctis V. Cortisol response to low dose versus standard dose (back-to-back) adrenocorticotrophic stimulation tests in children and young adults with thalassemia major. Indian J Endocrinol Metab. 2013 Nov;17(6):1046-52.

12 Kanbour I, Chandra P, Soliman A, De Sanctis V, Nashwan A, Abusamaan S, et al. Severe liver iron concentrations (LIC) in 24 patients with $\beta$-thalassemia major: correlations with serum ferritin, liver enzymes and endocrine complications. Mediterr J Hematol Infect Dis. 2018;10(1):e2018062.

13 Yassin MA, Soliman AT, De Sanctis V, Hussein RM, Al-Okka R, Kassem N, et al. Jadenu $®$ substituting Exjade $®$ in iron overloaded $\beta$-thalassemia major (BTM) patients: a preliminary report of the effects on the tolerability, serum ferritin level, liver iron concentration and biochemical profiles. Mediterr J Hematol Infect Dis. 2018 Nov; 10(1):e2018064.

14 Yassin MA, Soliman AT, de Sanctis V, Abdula MAJ, Riaz LM, Ghori FF, et al. Statural growth and prevalence of endocrinopathies in relation to liver iron content (LIC) in adult patients with beta thalassemia major (BTM) and sickle cell disease (SCD). Acta Biomed 2018;89(2-S):33-40.

15 Yassin MA, Soliman A, De Sanctis V, Hmissi SM, Abdulla MAJ, Ekeibed Y, et al. The impact of iron overload in patients with acute leukemia and myelodysplastic syndrome on hepatic and endocrine functions. Acta Biomed 2018;89(3-S):18-22.

16 Yassin M, Soliman A, De Sanctis V, Nashwan A, Abusamaan S, Moustafa A, et al. Liver iron content (LIC) in adults with sickle cell disease (SCD): correlation with serum ferritin and liver enzymes concentrations in transfusion dependent (TD-SCD) and non-transfusion dependent (NT-SCD) patients. Mediterr J Hematol Infect Dis. 2017;9(1):e2017037.

17 Yassin MA, Soliman AT, De Sanctis V, Yassin KS, Abdulla MA. Final height and endocrine complications in patients with $\beta$-thalassemia intermedia: our experience in non-transfused versus infrequently transfused patients and correlations with liver iron content. Mediterr J Hematol Infect Dis. 2019;11(1):e2019026.

18 Yassin MA, Soliman AT, Desanctis V, Abusamaan S, Elsotouhy A, Aldewik N. Hereditary hemochromatosis in an adult due to H63D mutation: the value of estimating iron deposition by MRI T2* and dissociation between serum ferritin concentration and hepatic iron overload. Blood. 2014;124(21):4891. 